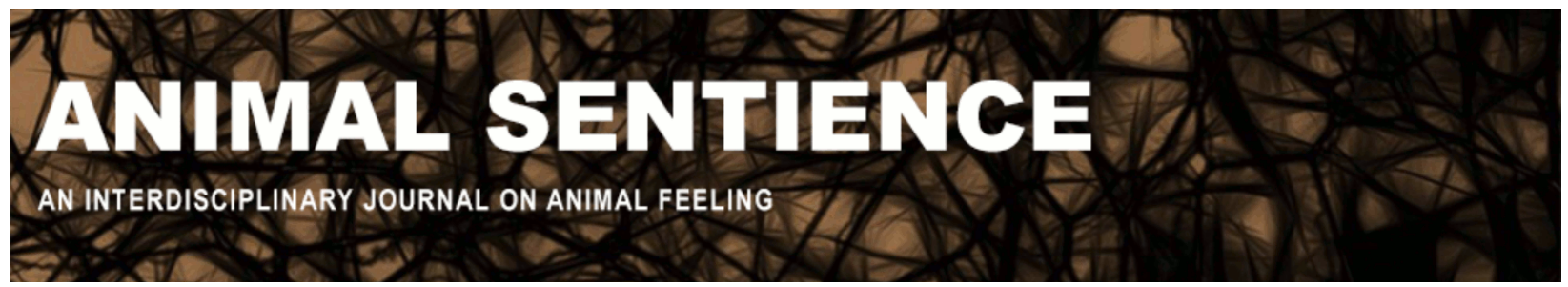

Cruse, Holk and Schilling, Malte (2016) No proof for subjective experience in insects. Animal Sentience 9(13)

DOI: $10.51291 / 2377-7478.1146$

Date of submission: 2016-08-15

Date of acceptance: 2016-08-19

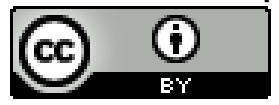

This article has appeared in the journal Animal

Sentience, a peer-reviewed journal on animal

cognition and feeling. It has been made open access,

free for all, by WellBeing International and deposited

in the WBI Studies Repository. For more information,

please contact

wbisr-info@wellbeingintl.org.

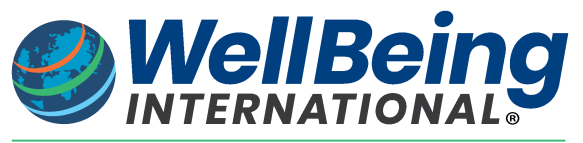

SOLUTIONS FOR PEOPLE, ANIMALS AND ENVIRONMENT 


\title{
No proof for subjective experience in insects
}

Commentary on Klein \& Barron on Insect Experience

\author{
Holk Cruse \\ Biology, Bielefeld University \\ Malte Schilling \\ Cognitive Interaction Technology, Bielefeld University
}

\begin{abstract}
Klein \& Barron (2016) provide an inspiring review collecting arguments that show quite related functions in humans and insects. Here we extend the comparison to robots, and formulate two critical objections. One concerns an epistemological question related to the phenomenon of subjective experience. The other questions whether insects need integrated spatiotemporal modeling for navigation.
\end{abstract}

Holk Cruse, Professor of Biology, Bielefeld University, was head of the Biological Cybernetics group from 1981 until 2009. His research focuses on the control of walking and navigation in insects, combining behavioral studies with computational modeling and simulation. One of his main interests is how emergent properties may arise that cannot be characterized at the level of description of neuronal structures alone.

http://www.uni-

bielefeld.de/biologie/Kybernetik/People/holk cruse.html

Malte Schilling is a Responsible Investigator at the Center of Excellence for Cognitive Interaction Technology at Bielefeld University. His work concentrates on mental representations, their grounding in behavior and their application in higher-level cognitive function such as planning or communication. https://www.cit-ec.de/en/es/schilling
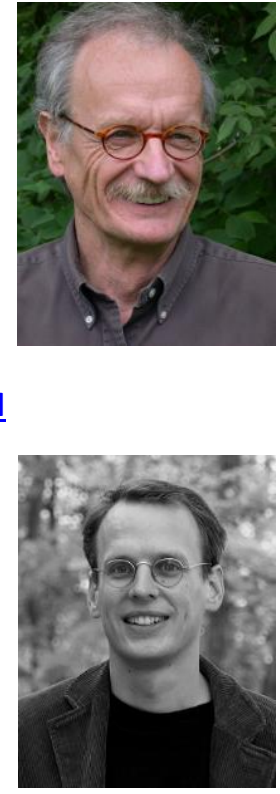

\section{Introduction}

Klein \& Barron (2016) (K \& B) and Barron \& Klein (2016) argue that in both vertebrate and insect lineages there is an integrated behavioral control system for effective decision making and action selection. On this basis the authors develop their proposition that subjective experience (sentience) arose as a consequence of such a system, leading to the idea that insects as vertebrates are equipped with the faculty of sentience.

We agree with the authors that counterarguments against insects as research models in neuroscience - as are often found in the literature - are not helpful. In particular, we too disagree with the common notion that (i) the number of neurons in insects is too small or (ii) that their brain does not show enough complexity to reach the level of consciousness. In addition, we support K \& B's statement that insect brains have been consistently underestimated. 


\section{Subjective experience, an epistemological problem}

$K \& B$, however, infer subjective experience from a functional similarity. Here we see an epistemological problem (cf. Schilling \& Cruse, 2016): We can be sure about subjective experience (or internal perspective or first person view) only for ourselves. Nobody, except myself, can feel my feelings. Even if the states of my brain were accessible to external observers, they could only observe the neuronal activities; they could not experience my feelings. They are "private." The external observer cannot even decide whether subjective experiences are being felt at all, or the subject is merely pretending. Among humans there is an indirect argument by analogy: All humans have the same kind of brain. As we assume that subjective experience results from properties of the brain, other humans should have the same properties as I. So, if I have subjective experience, they probably have it too.

But as we do not (yet) know what neural components and dynamics are required for this phenomenon to occur, we can only speculate regarding nonhuman subjects; this is also true for artificial systems. A possible experimental approach to this problem will briefly be described below.

\section{Comparison with artificial systems}

To support their thesis, $K \&$ B do a good job in marshalling evidence and arguments that show quite similar functions in humans and insects (their Figures 1 and 2 and related text). Here, we point out that such properties can also be found in robots, for example, in a network called reaCog that runs a hexapod robot (Cruse \& Schilling, 2015). This network does not rely on details of either mammalian or insect brains as sketched in K \& B's Figure 2. Rather, inspired by insect studies, the network implements basic properties of the insect motor control system, including action selection, decision making, navigation and learning. ReaCog contains what $K \& B$ describe as a "common final pathway for action planning." There is competition and cooperation between neuronal elements, and there is no place for a "Cartesian theatre," very much in agreement with what is known about insects.

However, reaCog has properties not (yet) found in insects such as planning ahead and inventing new solutions by exploiting the capacity for global access to memory information outside the current context. Using a holistic internal body model (Schilling et al., 2012), the system as a whole has capabilities like the ones $K \& B$ describe as the basis for a unified multimodal neuronal model of the agent within its environment. Thus, according to Barron \& Klein, reaCog should at least be equipped with subjective experience.

We did a systematic study of whether properties often attributed to consciousness can be found in reaCog. Once certain properties had been added to the network (Cruse \& Schilling 2015), there seemed to be a strong basis for inferring that the system showed some access consciousness and reflexive consciousness, but not for inferring phenomenal consciousness (i.e., subjective experience). This was because we have no idea yet what neural activities are responsible for producing subjective experience; this is what we mean by an epistemological problem. 


\section{In human beings, subjective experience is under competitive control}

The problem of relating function to subjective experience arises not only when comparing insects with vertebrates, or with robots. It also arises with the human brain as illustrated by the following example. The basic experiment was performed by Fehrer \& Raab (1962) and detailed studies followed (Neumann \& Klotz, 1994). Human participants first had to learn to press a button whenever a single square was shown on a screen, but not when two squares were shown on either side of the first square. The critical condition took place after the learning phase: the single square was presented very briefly (about $30 \mathrm{~ms}$ ) followed by a longer presentation of the two squares. The participants reported not having seen the single square, only the two squares. Yet they pressed the button.

This shows that the memory elicited first ("motor response to single-square stimulus") can be executed without being accompanied by subjective experience of the single square. It also shows that the memory "no motor response to double-square stimulus" influences whether the content of the first memory is experienced. This suggests that this memory inhibits the subjective experience of the first stimulus. (For a quantitative simulation see Cruse \& Schilling, 2015, Fig 8.)

From these observations in humans, we conclude that specific procedures may or may not be accompanied by subjective experience, which apparently requires more time and is under the control of other competing memories. This means that we cannot infer from function to subjective experience in humans. Hence, when we observe similar functions in insects and mammals, they may not be having subjective experiences either.

\section{Navigation using a decentralized architecture}

Another problem concerns the possible over-interpretation of data - in this case insect data. A specific example is $K$ \& B's comparison of nematodes and insects. We agree that nematodes are not able to navigate the way bees and ants can. However, the fascinating ability of bees and ants to navigate does not require $K \&$ B's "integrated spatiotemporal modeling." Navigation in ants and bees can be explained by relatively simple, decentralized neuronal structures (Cruse \& Wehner, 2011; Hoinville et al., 2012). There is no evidence that they can form "spatial relationships between arbitrary objects." Insects can learn (by vector navigation) a food location (by vector navigation) and they have local information that indicates where to move (based on local visual input). In reaCog, there is integration of sensation and action but there is no evidence that this is the case in insects (although it is sometimes postulated that information is "integrated in a common navigational reference"; Menzel et al., 2011). Thus, the key feature postulated by K \& B for subjective experience is not available for insects (based on the evidence to date).

\section{Conclusion}

So whereas we find K \& B's contribution extremely interesting and inspiring, we have two objections. One concerns the epistemological problem, the other an unjustified interpretation of the data. In our view, the only way to proceed would be to explore the detailed properties of neuronal structures that lead to subjective experience. But we can 
only do such studies with human subjects because only there can we be sure that subjective experience is occurring, and can be reported. Such a research program may reveal the necessary and sufficient conditions for a neural network to have subjective experience. Success would not solve the hard problem, but the knowledge gained would allow us to predict which features of our neuronal function generate subject experience. The ability to predict the occurrence of subjective experience may then be enough to give us the impression of having understood the phenomenon currently still dubbed the "hard problem" (Cruse, 1999, 2003).

\section{References}

Barron, A. B., \& Klein, C. (2016). What insects can tell us about the origins of consciousness. Proceedings of the National Academy of Science of the United States of America, 113(18), 4900-4908.

Cruse, H. (1999). Feeling our body - the basis of cognition? Evolution and Cognition, 5, 162173.

Cruse, H. (2003). The evolution of cognition - a hypothesis. Cognitive Science, 27, 135-155.

Cruse, H., \& Schilling, M. (2015). Mental states as emergent properties - From walking to consciousness. In T. Metzinger \& J. M. Windt (Eds.), Open MIND: 9(C). Frankfurt am Main: MIND Group. doi: 10.15502/9783958570436. http://open-mind.net/papers/mentalstates-as-emergent-properties-from-walking-to-consciousness/at download/paperPDF

Cruse, H., \& Wehner, R. (2011). No need for a cognitive map: Decentralized memory for insect navigation. PLoS Computational Biology, 7(3), e1002009.

Fehrer, E., \& Raab, D. (1962). Reaction time to stimuli masked by metacontrast. Journal of Experimental Psychology, 62(2), 143-147. doi: 10.1037/h0040795

Hoinville, T., Wehner, R., \& Cruse, H. (2012). Learning and retrieval of memory elements in a navigation task. In Biomimetic and biohybrid systems. First International Conference, Living Machines 2012, Barcelona, Spain, July 9-12, 2012, Proceedings. Series: Lecture Notes in Computer Science, Vol. 7375. Subseries: Lecture Notes in Artificial Intelligence. T.T. Prescott, N.F. Lepora, A. Mura, \& P.F.M.J. Verschure (Eds.), pp. 120-131. Springer, Berlin Heidelberg.

Klein, C. \& Barron, A. B. (2016). Insects have the capacity for subjective experience. Animal Sentience 2016.100.

Neumann, O., \& Klotz, W. (1994). Motor responses to non-reportable, masked stimuli: Where is the limit of direct parameter specification? In C. Umilta \& M. Moscovitch (Eds.), Attention and performance XV (pp. 123-150). Cambridge, MA: MIT Press.

Menzel, R., Kirbach, A., Haass, W.D., Fischer, B., Fuchs, J., Koblofsky, M., Lehmann, K., Reiter, L., Meyer, H., Nguyen, H., Jones, S., Norton, P., \& Greggers, U. (2011). A common frame of reference for learned and communicated vectors in honeybee navigation. Current Biology, 21, 645-650, April 26, 2011.

Schilling, M., \& Cruse, H. (2016). Avoid the hard problem: Employment of mental simulation for prediction is already a crucial step. Proceedings of the National Academy of Science of the United States of America, 113, E3811.

Schilling, M., Paskarbeit, J., Schmitz, J., Schneider, A., \& Cruse, H. (2012). Grounding an internal body model of a hexapod walker - Control of curve walking in a biological inspired robot. In Proceedings of IEEE/RSJ International Conference on Intelligent Robots and Systems, IROS 2012, pp. 2762-2768. 